\title{
Genome-Wide Integrative Analysis Reveals Common Molecular Signatures in Blood and Brain of Alzheimer's Disease
}

\author{
Md Rezanur Rahman 1,2,*(D), Tania Islam 2 (iD), Md Shahjaman ${ }^{3}$ (D), Md Humayun Kabir Rana 4(D), R.M.

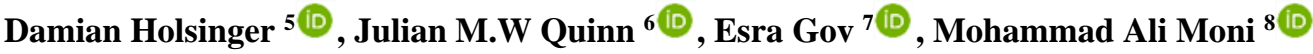

1 Department of Biochemistry and Biotechnology, School of Biomedical Science, Khwaja Yunus Ali University, Sirajgonj, Bangladesh; rezanur12@yahoo.com (M.R.R.);

2 Department of Biotechnology and Genetic Engineering, Islamic University, Kushtia, Bangladesh; taniaislam1304@gmail.com (T.I.);

3 Department of Statistics, Begum Rokeya University, Rangpur, Bangladesh; shahjaman_brur@yahoo.com (M.S.);

4 Department of Computer Science and Engineering, Green University of Bangladesh, Bangladesh; humayan.pustcse@ gmail.com (M.H.K.R.);

5 Discipline of Biomedical Science, School of Medical Sciences, Faculty of Medicine and Health, The University of Sydney, Sydney, NSW, Australia; damian.holsinger@sydney.edu.au (R.M.D.H.);

6 Bone Biology Division, Garvan Institute of Medical Research, Darlinghurst, NSW, Australia; j.quinn@garvan.org.au (J.M.W.Q.);

7 Department of Bioengineering, Adana Alparslan Turkes Science and Technology University, Adana, Turkey; egov@atu.edu.tr (E.G.);

8 WHO Collaborating Centre on eHealth, School of Public Health and Community Medicine, Faculty of Medicine, The University of New South Wales, Sydney, Australia; m.moni@unsw.edu.au (M.A.M.);

* Correspondence: rezanur12@yahoo.com;

Scopus Author ID 55457981300

Received: 6.07.2020; Revised: 2.08.2020; Accepted: 4.08.2020; Published: 8.08.2020

Abstract: The currently utilized neuroimaging and cerebrospinal fluid-based detection of Alzheimer's disease (AD) suffer several limitations, including sensitivity, specificity, and cost. Therefore, the identification of $\mathrm{AD}$ by analyzing blood gene expression may ameliorate the early diagnosis of the AD. We aimed to identify common genes commonly deregulated in blood and brain in AD. Comprehensive analysis of blood and brain gene expression datasets of $\mathrm{AD}$, eQTL, and epigenetics data was analyzed by the integrative bioinformatics approach. The integrative analysis showed nine differentially expressed genes common to blood cells and brain (CNBD1, SUCLG2-AS1, CCDC65, PDE4D, MTMR1, C3, SLC6A15, LINC01806, and FRG1JP). Analysis of SNP and cis-eQTL data showed 18 genes; namely, HSD17B1, GAS5, RPS5, VKORC1, GLE1, WDR1, RPL12, MORN1, RAD52, SDR39U1, NPHP4, MT1E, SORD, LINC00638, MCM3AP-AS1, GSDMD, RPS9, and GNL2 were observed deregulated $\mathrm{AD}$ blood and brain tissues. Functional gene set enrichment analysis demonstrated a significant association of these genes in neurodegeneration-associated molecular pathways. Integrative biomolecular networks revealed dysregulation of several hub transcription factors and microRNAs in AD. Moreover, hub genes were observed associated with significant histone modification. This study detected common molecular biomarkers and pathways in blood and brain tissues in $\mathrm{AD}$ that may be potential biomarkers and therapeutic targets in $\mathrm{AD}$.

Keywords: Alzheimer's disease; molecular signature; blood-brain common gene; differentially expressed genes; protein-protein interactions; epigenetics.

(C) 2020 by the authors. This article is an open-access article distributed under the terms and conditions of the Creative Commons Attribution (CC BY) license (https://creativecommons.org/licenses/by/4.0/). 


\section{Introduction}

Alzheimer's disease (AD) is a progressive neurodegenerative disease common among elderly individuals that results in progressively severe cognitive impairment. In the USA, 5.7 million people are currently living with Alzheimer's, and this is expected to rise to 14 million by 2050 [1-3]. AD is diagnosed by the presence of extracellular amyloid plaques and intracellular neurofibrillary tangles in the brain and reacts the pathobiological processes that underlie the disease [3-4]. Although the pathogenesis of $\mathrm{AD}$ is multifactorial in nature, the application of molecular methods to improve diagnosis and assessment of $\mathrm{AD}$ has yet to provide substantiated results, and hence the quest for early AD biomarkers in peripheral blood has received increased attention [3,5]. Successful identification of such blood molecular biomarkers will have a high impact on AD diagnosis, care, and treatment [3].

Positron emission tomography (PET) based neuroimaging techniques, and cerebrospinal fluids are both used in clinical practice to diagnose Alzheimer's [6-7]. However, these procedures suffer serious limitations, including the invasiveness of collecting CSF as well as the sensitivity, specificity, cost, and limited access to neuroimaging [8]. Considering the shortcomings of available resources for the detection of neurodegenerative diseases, many studies have attempted to explore biomarkers in the blood of AD patients [1,3,6,9]. Circulating cells and proteins are easily accessible from fresh blood samples; the collection procedure is less invasive. Since central mechanisms underlying the progression of the disease is still not clear, much attention has been drawn to systems biology approaches as a new avenue to elucidate the possible roles of biomolecules in complex diseases such as AD [1,3,9-11]. For example, evidence of involvement of miRNA deregulation in the development of neurodegenerative diseases [10]. Consequently, biomolecules such as mRNAs, transcription factors (TFs), miRNAs (and mRNA gene transcripts targeted by such TFs and miRNAs) are increasingly being scrutinized for use as new biomarkers for AD. In addition, the role of epigenetic modifications is also a focus of much interest, with evidence for their importance in the development and progression of AD [12]. DNA methylation and histone modifications are common mechanisms for epigenetic regulation of gene expression [12]. It is well understood that factors such as lifestyle, age, environment, and co-morbid states effect epigenetic changes as well as the risk of $\mathrm{AD}$ and that gene methylation and histone modification may be implicated as mediators [12].

We employed an integrative approach to identify molecular biomarker signatures that are expressed under similar genetic control in blood cells and the brain in AD using transcriptome and expressed quantitative loci (cis-eQTL). Gene over-representation analysis was performed on core DEGs followed by gene ontology (GO) analysis. Pathway analysis was then used to enrich the DEGs. Core DEGs were further analyzed to identify regulatory factors (TFs, miRNAs) that may affect the DEG in AD-affected tissues, as well as analysis to identify histone modification sites within the identified DEGs. This study specifically focused on biomarker signatures at both transcriptional (mRNAs and miRNAs), and translational levels (hub proteins and TFs) as our intention was to present valuable information that would clarify mechanisms in AD that may provide e_cacious potential biomarkers for early diagnosis and systems medicines (Figure 1). 


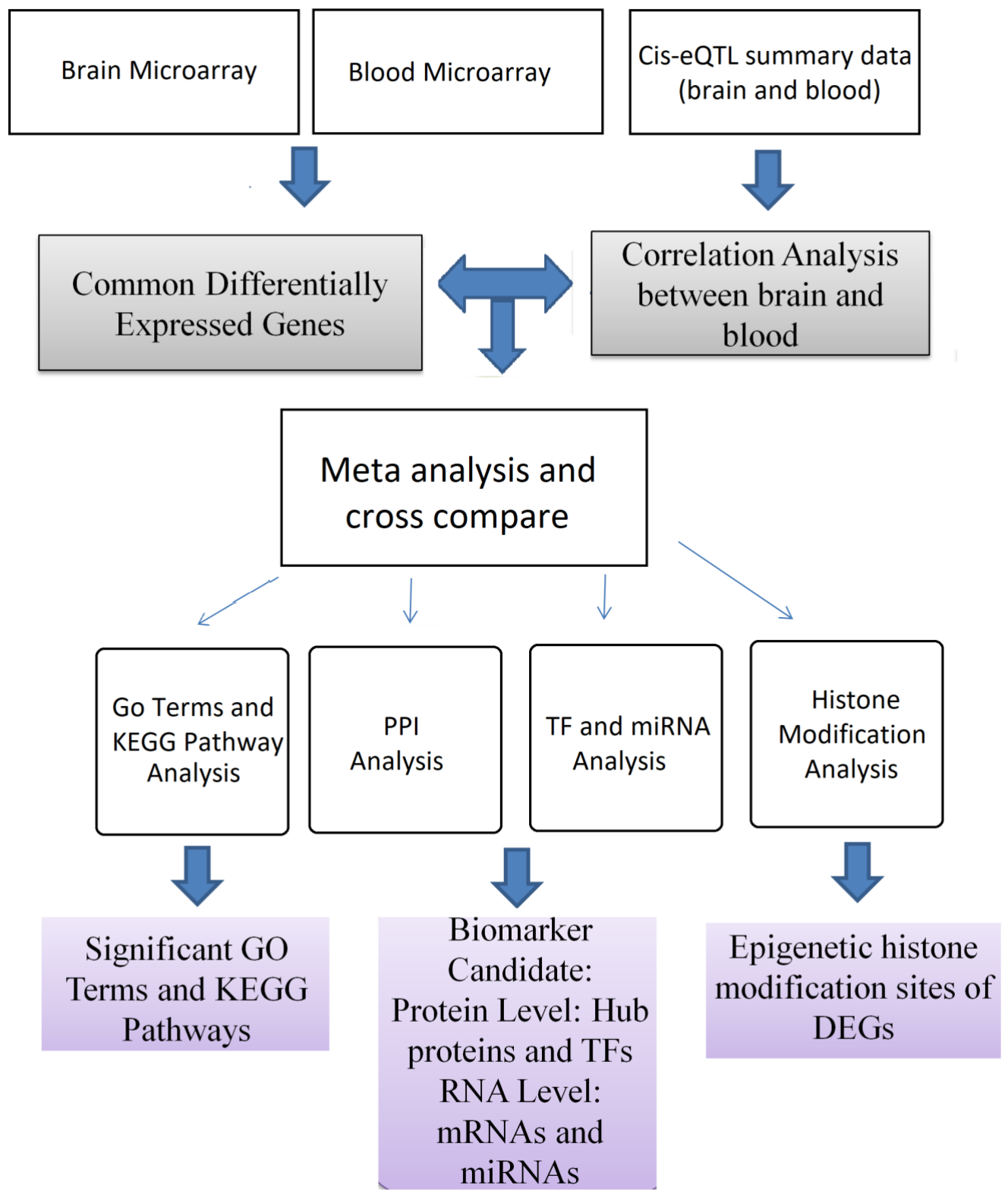

Figure 1. The systems biology pipeline employed in this study. Gene expression datasets of the blood of AD were obtained from the GEO and GTEx portal. The datasets were analyzed using in Bioconductor environment in R to identify common DEGs between brain and blood tissue. The significantly enriched pathways, GO terms were identified through functional enrichment analyses. PPI network was constructed to identify hub proteins. TF-target gene interactions and miRNA-target genes interactions were studied to identify regulatory biomolecules.

\section{Materials and Methods}

\subsection{Identification of differentially expressed genes from microarray datasets.}

We obtained two gene expression microarray datasets GSE18309 (peripheral blood mononuclear cells (PBMCs) expression dataset) and GSE4757 (brain tissue) of AD patients from NCBI-GEO database [13]. The peripheral blood tissue datasets (PBMCs) contained 6 samples where 3 samples were $\mathrm{AD}$ blood tissues of $\mathrm{AD}$ while 3 were matched control (excluded 3 mild cognitive impairment samples from analysis). The brain tissues dataset 
GSE4757 had 20 samples where matched pair samples of AD from neurons were obtained. The gene expression profile of 10 mid-stage $\mathrm{AD}$ of the entorhinal cortex containing neurofibrillary tangles and 10 paired normal neurons (without neurofibrillary tangles). We applied a logarithmic transformation to both blood and brain microarray datasets to approximate the datasets to normality and to mitigate the effect of outliers. Following this, we applied linear Models for Microarray (limma) through the bioconductor platform in R in order to identify the DEGs from each dataset. The overlapping DEGs between the two datasets were considered for further analysis. We then screened for statistically significant DEGs that satisfied an adjusted p-value $<$ 0:05 and absolute values of $\log 2$ fold for control $>=1: 0$. The Benjamini-Hochberg (BH) method was used to adjust p-values.

\subsection{Geneset enrichment analyses to identify gene ontology and molecular pathways.}

We performed gene set enrichment analysis via Enrichr [14] to identify GO and pathways of the overlapping DEGs. The ontology comprised of three categories: biological process, molecular function, and cellular component. The $\mathrm{p}$-value $<$ 0:05 was considered as the cut-off criterion for all enrichment analyses.

\subsection{Protein-protein interaction network analysis.}

We retrieved the PPI networks based on the physical interaction of the proteins of DEGs using STRING database [15]. A confidence score of 900 was selected in the STRING Interactome. Network visualization and topological analyses were performed through NetworkAnalyst [16]. Using topological parameters, the degree (greater than equal 18 degrees) was used to identify highly interacting hub proteins from PPI analysis.

\subsection{Identification of histone modification sites.}

Histone modification data for the hub genes were retrieved from the human histone modification database (HHMD) [17]. HHMD is a public repository that contains human histone modifications information obtained from experimental studies.

2.5. Identification of transcriptional and post-transcriptional regulators of the differentially expressed genes.

We used TF-target gene interactions from TRANSFAC [18] and JASPAR databases [19] to identify TFs. The miRNA-target gene interactions were obtained from miRTarBase [20]. We have considered statistically signi_cant miRNAs and TFs with $(\mathrm{p}<0: 05)$ computed by Fishers' exact test via Enrichr [14].

\section{6. eQTL effects between blood and brain tissues.}

We used eQTL data of both blood and brain from the GTEx Portal, which is a database for Genetic Association data (https: //gtexportal.org/home/). These eQTL databases link gene SNPs to gene expression. We used them to identify genes with similar genetic control of expression in the two tissues using meta-analysis approaches.

If we allow $x^{\sim}$ to be the estimated effect of the top-linked cis-eQTL for a gene, we can calculate $x^{\sim}$ based on the method explained in [21] and as below:

$$
\tilde{x}=x+Q
$$


where $x$ is the true effect, and $Q$ is the estimated error. The covariance of the estimated ciseQTL effects between tissues $i$ and $j$ across genes can be partitioned into the co-variance of true cis-QTL effects and the co-variance of estimation errors. Thus we can estimate the correlation of true cis-eQTL effect sizes across genes between tissues $\mathrm{i}$ and $\mathrm{j}$.

\subsection{Cross-validation of the differential expression of differentially expressed genes.}

We utilized an independent whole blood gene expression dataset of advanced AD cases and controls (GEO accession, GSE97760). The demographic summary and details of the patients are described in the respective publication (PMID: 25079797). However, the dataset had nine advanced $\mathrm{AD}$ cases and 10 age-matched healthy who are all females. The gene expression data were normalized by log-transformation and quantile normalization using the Limma package in the Bioconductor environment in $\mathrm{R}$ implemented in the RStudio.

\subsection{Statistical analysis.}

The data visualization of differential expression was done via GraphPad Prism 5.

\section{Results and Discussion}

\subsection{Identification of common deferentially expressed genes between blood and brain tissues.}

We analyzed microarray gene expression datasets of the brain and blood samples of AD patients. The analysis revealed 9 (nine) common DEGs (CNBD1, SUCLG2-AS1, CCDC65, PDE4D, MTMR1, C3, SLC6A15, LINC01806, and FRG1JP) in blood and brain. We also identified AD-associated genes in the blood that mirror those in brain from eQTL. We used a meta-analysis approach to identify genes from GTEx database that display a similar expression pattern in both blood and brain tissues using eQTL database that link gene variants (SNPs) to gene expression. Thus, we identified 673 blood-brain co-expressed genes (BBCG) using the correlation and meta-analysis approach, as explained in the methods section. We identified 18 DEGs (HSD17B1, GAS5, RPS5, VKORC1, GLE1, WDR1, RPL12, MORN1, RAD52, SDR39U1, NPHP4, MT1E, SORD, LINC00638, MCM3AP-AS1, GSDMD, RPS9, and GNL2) that were commonly dysregulated between $\mathrm{AD}$ blood and brain compared to control tissues using SNP and cis-eQTL data of curated, gold-benchmarked OMIM and GWAS catalogs. In this way, we have identified 27 DEGs that were commonly dysregulated in blood and brain in AD from microarray and eQTL data analysis. To clarify the biological significance of the identified DEGs, we performed a gene set enrichment analysis. The significant GO terms were enriched in biological processes, molecular functions, and cellular components (Table 1). The pathways analysis revealed significant pathways in the Ribosome, Alternative Complement Pathway, Classical Complement Pathway, Lectin Induced Complement Pathway, and Cytoplasmic Ribosomal Proteins (Table 2).

Table 1. Gene Ontology (biological process, cellular component, and molecular functions) of dysregulated genes common to blood cells and brain tissue of Alzheimer's disease.

\begin{tabular}{l|l|l|l|l} 
Category & GO ID & Term & $\begin{array}{l}\text { Adjusted } \\
\text { value }\end{array}$ & $\begin{array}{l}\text { Genes } \\
\text { Biological } \\
\text { process }\end{array}$ \\
\cline { 2 - 4 } & GO:0045047 & protein targeting to ER & 0.014 \\
\cline { 2 - 4 } & GO:0006614 & $\begin{array}{l}\text { SRP-dependent cotranslational protein targeting } \\
\text { to membrane }\end{array}$ & 0.014 & RPS9;RPL12;RPS5 \\
\cline { 2 - 4 } & $\begin{array}{l}\text { nuclear-transcribed mRNA catabolic process, } \\
\text { nonsense-mediated decay }\end{array}$ & 0.014 & RPS9;RPL12;RPS5
\end{tabular}




\begin{tabular}{l|l|l|l|l}
\hline \multirow{2}{*}{ Category } & GO ID & Term & $\begin{array}{l}\text { Adjusted } \\
\text { value }\end{array}$ & Genes \\
\hline \multirow{4}{*}{$\begin{array}{l}\text { Cellular } \\
\text { component }\end{array}$} & GO:0019083 & viral transcription & 0.014 & RPS9;RPL12;RPS5 \\
\cline { 2 - 5 } & GO:0019080 & viral gene expression & 0.014 & RPS9;RPL12;RPS5 \\
\cline { 2 - 5 } & GO:0005840 & ribosome & 0.004 & RPS9;RPL12;RPS5 \\
\cline { 2 - 5 } & GO:0022626 & cytosolic ribosome & 0.01 & RPS9;RPL12;RPS5 \\
\cline { 2 - 5 } & GO:0022627 & cytosolic part & 0.014 & RPS9;RPL12;RPS5 \\
\cline { 2 - 5 } & GO:0015935 & small ribosomal subunit & 0.015 & RPS9;RPS5 \\
\hline $\begin{array}{l}\text { Molecular } \\
\text { function }\end{array}$ & GO:0019843 & rRNA binding & 0.015 & RPS9;RPS5 \\
\hline
\end{tabular}

Table 2. The significant molecular pathways of common dysregulated genes between blood and brain tissue of

\begin{tabular}{l|l|l|l}
\multicolumn{4}{|c}{ Alzheimer's disease. } \\
Category & Pathways & Adj. P-value & Genes \\
\hline KEGG & Ribosome & 0.021 & RPS9;RPL12;RPS5 \\
\hline \multirow{2}{*}{ BioCarta } & Alternative Complement Pathway & 0.02 & C3 \\
\cline { 2 - 4 } & Classical Complement Pathway & 0.02 & C3 \\
\cline { 2 - 4 } & Lectin Induced Complement Pathway & 0.02 & C3 \\
\hline \multirow{2}{*}{ WikiPathways } & Cytoplasmic Ribosomal Proteins & 0.005 & RPS9;RPL12;RPS5
\end{tabular}

3.2. Protein-protein interaction analysis to identify hub proteins.

A protein-protein interaction network was constructed, encoded by the DEGs to reveal the central protein, the so-called hub proteins considering the degree measures (Figure 2). RPS5, RPL12, RPS9, GNL2, PDE4D, and WDR1 were identified as the hub proteins. These are potential biomarkers and may lead to new AD therapeutic targets.

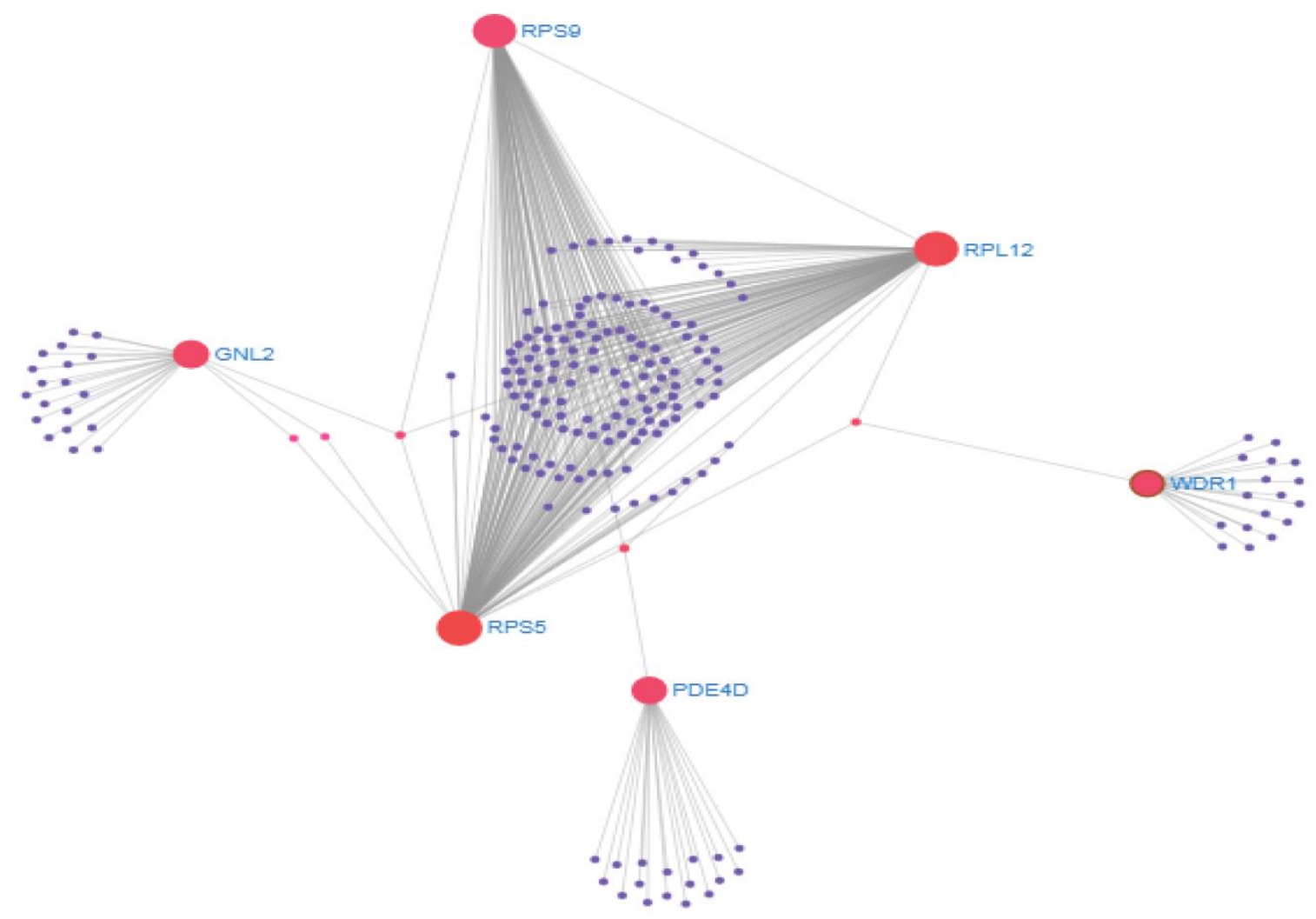

Figure 2. Protein-protein interaction network of the differentially expressed genes (DEGs) in Alzheimer's disease. The nodes indicate the DEGs and the edges indicate the interactions between two genes. 


\subsection{Epigenetic regulation of the differentially expressed genes.}

In order to identify the probable epigenetic regulation of the hub genes, histone modification data for six of eight hub genes (Table 3) were retrieved from HHMD. Table 3 shows that all the hub genes were associated with several histone modification sites.

\begin{tabular}{c|c|c|c|c|c|c} 
Table 3. Histone modification of hub genes in neurodegenerative diseases. \\
$\begin{array}{c}\text { Official Symbol } \\
\text { of DEGs and } \\
\text { Hub Genes }\end{array}$ & RefSeq ID & Histone modification sites already known in neurodegenerative diseases \\
\cline { 4 - 7 } & & H3K27 & H3K4 & H3K9 & H3K9/H4K20 & H4R3 \\
\hline RPS5 & NM_001009 & $\checkmark$ & $\checkmark$ & $\checkmark$ & $\checkmark$ & $\checkmark$ \\
\hline PDE4D & NM_001104631 & $\checkmark$ & $\checkmark$ & $\checkmark$ & $\checkmark$ & $\checkmark$ \\
\hline RPL12 & NM_000976 & $\checkmark$ & $\checkmark$ & $\checkmark$ & $\checkmark$ & $\checkmark$ \\
\hline RPS9 & NM_001013 & $\checkmark$ & $\checkmark$ & $\checkmark$ & $\checkmark$ & $\checkmark$ \\
\hline GNL2 & NM_013285 & $\checkmark$ & $\checkmark$ & $\checkmark$ & $\checkmark$ & $\checkmark$ \\
\hline WDR1 & NM_017491 & $\checkmark$ & $\checkmark$ & $\checkmark$ & $\checkmark$ & $\checkmark$
\end{tabular}

\subsection{Identification of post-transcriptional regulator.}

We identified TFs and miRNAs interacted with DEGs to reveal regulatory biomolecules that may regulate the expression of DEGs at transcriptional and posttranscriptional levels (Figure 3 and Table 4-5). The analysis revealed signi_cant TFs (SREBF2, NR1H2, NR1H3, 138 PRDM1, and XBP1) and miRNAs (miR-518e, miR-518a-3p, miR-518b, miR-518c, miR-139 518d-3p, and miR-518f) played signi_cant roles in the regulation of the DEGs identi_ed this study.

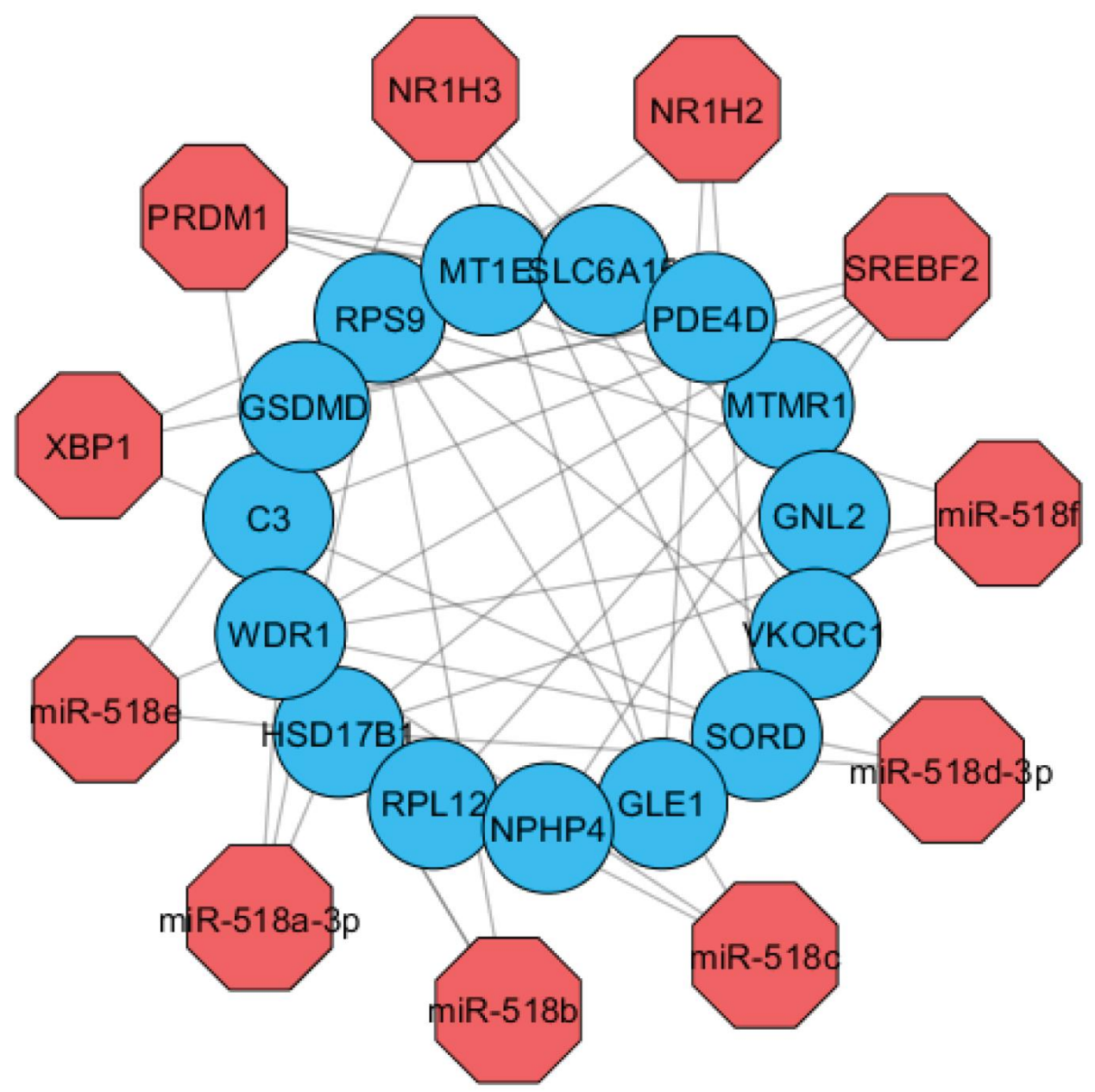

Figure 3. Interaction networks of gene with regulatory biomolecules (transcription factors and miRNAs). 
Table 4. Biomolecules comprising transcription factors and MicroRNAs may regulate commonly dysregulated genes in Alzheimer's disease.

Biomolecules

Target Genes

P-value

\begin{tabular}{l|c|c}
\multicolumn{1}{l}{ Biomolecules } & Target Genes & P-value \\
\hline SREBF2 & Transcription Factor & 0.008 \\
\hline NR1H2 & GSDMD;C3;WDR1;HSD17B1;RPL12;NPHP4 & 0.02 \\
\hline NR1H3 & GLE1;GSDMD;SORD & 0.03 \\
\hline PRDM1 & GSDMD;VKORC1;GLE1;SORD;GNL2 & 0.04 \\
\hline XBP1 & MTMR1;WDR1;PDE4D;SLC6A15;MT1E & 0.04 \\
\hline \multicolumn{2}{|c|}{ MicroRNA } & 0.01 \\
\hline miR-518e & RPS9;WDR1;HSD17B1 & 0.02 \\
\hline miR-518a-3p & RPS9;WDR1;HSD17B1 & 0.02 \\
\hline miR-518c & RPS9;WDR1;HSD17B1 & 0.02 \\
\hline miR-518d-3p & RPS9;WDR1;HSD17B1 & 0.02 \\
\hline miR-518f & RPS9;WDR1;HSD17B1 & 0.02
\end{tabular}

Table 5. A list of biomolecules proposed in the present study for Alzheimer's disease.

\begin{tabular}{|c|c|c|c|}
\hline $\begin{array}{l}\text { Biomarker } \\
\text { Candidate }\end{array}$ & Name & $\begin{array}{l}\text { Relevance with } \mathrm{AD} \text { and neurodegenerative } \\
\text { diseases }\end{array}$ & Novelty \\
\hline \multicolumn{4}{|c|}{ Differentially Expressed Genes } \\
\hline CNBD1 & $\begin{array}{l}\text { Cyclic Nucleotide Binding Domain } \\
\text { Containing } 1\end{array}$ & $\begin{array}{l}\text { Associated with alcoholism and Diabetes mellitus } \\
\text { type } 2\end{array}$ & Novel \\
\hline SUCLG2-AS1 & SUCLG2 Antisense RNA 1 & Associated with gastric cancer according & Novel \\
\hline CCDC65 & Coiled-Coil Domain Containing 65 & Associated with ciliary dyskenesia & Novel \\
\hline PDE4D & Phosphodiesterase 4D & $\begin{array}{l}\text { PDE4D, which in preclinical research has been } \\
\text { suggested to be of particular importance for } \\
\text { cognition, in the hippocampus of a patient with } \mathrm{AD}\end{array}$ & Known \\
\hline MTMR1 & Myotubularin Related Protein 1 & $\begin{array}{l}\text { Diseases associated with include Charcot-Marie- } \\
\text { Tooth Disease }\end{array}$ & Novel \\
\hline $\mathrm{C} 3$ & Complement C3 & $\begin{array}{l}\text { Macular Degeneration, Hip, Cholesterol, } \\
\text { Echocardiography }\end{array}$ & Novel \\
\hline SLC6A15 & Solute Carrier Family 6 Member 15 & $\begin{array}{l}\text { Diseases associated include Major Depressive } \\
\text { Disorder }\end{array}$ & Novel \\
\hline LINC01806 & $\begin{array}{l}\text { Long Intergenic Non-Protein } \\
\text { Coding RNA } 1806\end{array}$ & a liated with the non-coding RNA class & Novel \\
\hline FRG1JP & $\begin{array}{l}\text { FSHD Region Gene } 1 \text { Family } \\
\text { Member J, Pseudogene }\end{array}$ & Pseudogene & Novel \\
\hline HSD17B1 & $\begin{array}{l}\text { Hydroxysteroid } \\
\text { Dehydrogenase } 1\end{array}$ & $\begin{array}{l}\text { Diseases associated with Acute T Cell Leukemia and } \\
\text { Acute Closed-Angle Glaucoma }\end{array}$ & Novel \\
\hline GAS5 & Growth Arrest Speci c 5 & 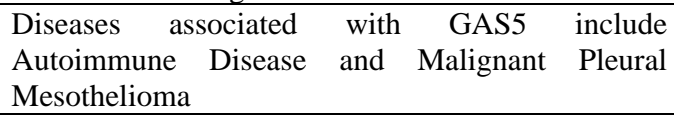 & Novel \\
\hline RPS5 & Ribosomal Protein S5 & Involved in retinitis pigmentosa & Novel \\
\hline VKORC1 & $\begin{array}{l}\text { Vitamin K Epoxide Reductase } \\
\text { Complex Subunit } 1\end{array}$ & $\begin{array}{l}\text { Genetic polymorphism is associated with } \\
\text { cardiovascular and neurodegenerative disease in } \mathrm{AD}\end{array}$ & Novel \\
\hline GLE1 & GLE1, RNA Export Mediator & $\begin{array}{l}\text { GLE1 mutations cause lethal congenital contracture } \\
\text { syndrome, a severe autosomal recessive fetal motor } \\
\text { neuron disease, and more recently, have been } \\
\text { associated with amyotrophic lateral sclerosis. }\end{array}$ & Known \\
\hline WDR1 & WD Repeat Domain 1 & $\begin{array}{l}\text { associated with adaptive immunity highlighting its } \\
\text { central role immunologic synapses }\end{array}$ & Novel \\
\hline RPL12 & Ribosomal Protein L12 & $\begin{array}{l}\text { Gene Ontology annotations related to gene RPS12 } \\
\text { include structural constituent of ribosome }\end{array}$ & Novel \\
\hline MORN1 & MORN Repeat Containing 1 & $\begin{array}{l}\text { Diseases associated with MORN1 include } \\
\text { Hemangioma of Lung }\end{array}$ & Novel \\
\hline RAD52 & $\begin{array}{l}\text { RAD52 Homolog, DNA Repair } \\
\text { Protein }\end{array}$ & $\begin{array}{l}\text { high concentrations of amyloid-beta inhibit the } \\
\text { expression and DNA damage response of RAD52 }\end{array}$ & known \\
\hline SDR39U1 & $\begin{array}{ll}\text { Short } & \text { Chain } \\
\text { Dehydrogenase/Reductase } & \\
\text { Family 39U Member 1 } & \\
\end{array}$ & $\begin{array}{l}\text { Gene Ontology (GO) annotations related to this gene } \\
\text { include oxidoreductase activity and coenzyme } \\
\text { binding }\end{array}$ & Novel \\
\hline NPHP4 & Nephrocystin 4 & $\begin{array}{l}\text { Diseases associated } \\
\text { Nephronophthisis } 4\end{array}$ & Novel \\
\hline MT1E & Metallothionein 1E & $\begin{array}{l}\text { related pathways are Metallothioneins bind metals } \\
\text { and Metabolism }\end{array}$ & Novel \\
\hline
\end{tabular}




\begin{tabular}{|c|c|c|c|}
\hline $\begin{array}{l}\text { Biomarker } \\
\text { Candidate }\end{array}$ & Name & $\begin{array}{l}\text { Relevance with AD and neurodegenerative } \\
\text { diseases }\end{array}$ & Novelty \\
\hline \multicolumn{4}{|c|}{ Differentially Expressed Genes } \\
\hline SORD & Sorbitol Dehydrogenase & $\begin{array}{l}\text { Diseases associated include Cataract and } \\
\text { Microvascular Complications of Diabetes }\end{array}$ & Novel \\
\hline LINC00638 & $\begin{array}{l}\text { Long Intergenic Non-Protein Coding } \\
\text { RNA } 638\end{array}$ & the non-coding RNA class & Novel \\
\hline $\begin{array}{l}\text { MCM3AP- } \\
\text { AS1 }\end{array}$ & MCM3AP Antisense RNA 1 & $\begin{array}{l}\text { Diseases associated with MCM3AP-AS1 include } \\
\text { Glioblastoma }\end{array}$ & Novel \\
\hline GSDMD & Gasdermin D & $\begin{array}{l}\text { related pathways are Apoptosis and Autophagy and } \\
\text { Innate Immune System }\end{array}$ & Novel \\
\hline RPS9 & Ribosomal Protein S9 & $\begin{array}{l}\text { Gene Ontology annotations related to gene RPS9 } \\
\text { include structural constituent of ribosome }\end{array}$ & Novel \\
\hline GNL2 & G Protein Nucleolar 2 & GNL2 plays a role in the neurogenesis of retina & Novel \\
\hline \multicolumn{4}{|c|}{ Transcription Factors } \\
\hline SREBF2 & $\begin{array}{l}\text { Sterol Regulatory Element Binding } \\
\text { Transcription Factor } 2\end{array}$ & Increased expression at mRNA levels in $\mathrm{AD}$ & Known \\
\hline NR1H3 & $\begin{array}{lrrr}\text { Nuclear Receptor } & \text { Subfamily } & 1 \\
\text { Group H Member } 3 & & \end{array}$ & $\begin{array}{l}\text { The genetic variant was studied to determine the e } \\
\text { ects of rs } 7120118 \text { variation in the NR1H3 gene } \\
\text { on the progression of AD }\end{array}$ & Known \\
\hline NR1H2 & $\begin{array}{lrrr}\text { Nuclear } & \text { Receptor } & \text { Subfamily } & 1 \\
\text { Group H Member } 2 & & \\
\end{array}$ & $\begin{array}{l}\text { The genetic polymorphism in NR1H2 may } \\
\text { contribute to the pathogenesis of AD }\end{array}$ & Novel \\
\hline PRDM1 & PR/SET Domain 1 & $\begin{array}{l}\text { The exome sequencing and functional studies } \\
\text { revealed the genetic variants of PRDM1 in Crohn's. } \\
\text { associated with } \\
\text { systemic lupus erythematosus }\end{array}$ & Novel \\
\hline WDR1 & WD Repeat Domain 1 & $\begin{array}{l}\text { WDR1 is associated with adaptive immunity } \\
\text { highlighting its central role immunologic synapses }\end{array}$ & Novel \\
\hline GN12 & G Protein Nucleolar 2 & $\begin{array}{l}\text { GNL2 plays a role in the neurogenesis of retina in } \\
\text { Zebra sh }\end{array}$ & Novel \\
\hline XBP1 & X-Box Binding Protein 1 & $\begin{array}{l}\text { The role of XBP1 in neurodegeneration remains } \\
\text { controversial and appears to be disease-specific }\end{array}$ & Novel \\
\hline \multicolumn{4}{|c|}{ MicroRNAs } \\
\hline $\operatorname{miR}-518 \mathrm{e}$ & MicroRNA 518 & $\begin{array}{l}\text { roles have been suggested for miR-518e and miR- } \\
518 \mathrm{a}-3 \mathrm{p} \text { in } \mathrm{AD}\end{array}$ & Known \\
\hline $\operatorname{miR}-518 a-3 p$ & MicroRNA 518a & $\begin{array}{l}\text { roles have been suggested for miR-518e and miR- } \\
518 \mathrm{a}-3 \mathrm{p} \text { in } \mathrm{AD}\end{array}$ & Known \\
\hline miR-518b & MicroRNA 518b & dysregulated in esophageal carcinoma & Novel \\
\hline miR-518c & MicroRNA 518c & biomarker for Parkinson's disease & Known \\
\hline $\operatorname{miR}-518 d-3 p$ & MicroRNA 518d & $\begin{array}{l}\text { Predicted as a therapeutic target in Huntington's } \\
\text { disease }\end{array}$ & Known \\
\hline miR-518f & MicroRNA518f & RNA gene an icted with RNA class & Novel \\
\hline
\end{tabular}

3.5. Cross-validation of the differentially expressed genes in independent blood gene expression data.

The differential expression of identified genes that show common deregulation in blood and brain gene expression dataset GSE97760, we performed cross-validation with an independent gene expression data of advanced AD patients compared to a matched control. 13 DEGs were consistently identi_ed in this independent advanced stage AD dataset overlapped with our results (Figure 4 and Table 6).

\subsection{Discussion.}

The lack of peripheral blood biomarkers for AD has led to a race to identify muchneeded evidence for the early diagnosis of this debilitating disease. The identification of peripheral biomarkers may also shed light on molecular mechanisms of AD and enable the monitoring of treatment. Advances in biomedical technology have spurred discoveries in numerous research areas. Microarray analysis is widely used in biomedical research and is considered the main resource for candidate biomarkers. Microarray databases contain a wealth of untapped genomic information. We analyzed two gene expression datasets from peripheral 
blood and brain of the AD patients in an attempt to identify potential biomarker candidates. Our analysis revealed 27 DEGs common dysregulated to the blood and brain of AD patients. We cross-compared the differential expression of these identified DEGs in available blood gene expression from advanced AD cases compared to controls. The comparison showed 13 DEGs were consistently deregulated in the cross-validation dataset suggesting the reliability of the identified candidate biomarkers and corroborates the employed approach.

Gene set enrichment analyses also revealed $\mathrm{AD}$-associated molecular signaling pathways that included the ribosome and complement systems. Employing protein-protein interaction networks, we also identified dysregulated central hub proteins that control many cellular processes. These hub proteins are considered key drivers in the mechanisms underlying the disease [22]. Therefore, we reconstructed the protein interaction network focusing on the DEGs in an attempt to identify related hub proteins. Such proteins have the potential to contribute to the formation and progression of AD. Of the DEGs we identified, mRNA levels of RPS5, a ribosomal protein, has been shown to be increased in the frontal cortex of AD subjects and AD transgenic mice [23].

Epigenetic alterations are present in different tissues during aging, as well as in neurodegenerative disorders such as $\mathrm{AD}$. AD-related genes exhibit epigenetic changes, indicating that epigenetics might contribute to pathogenic changes observed in dementia. Epigenetic modifications are reversible and may potentially be targeted by pharmacological intervention [24]. We have identified epigenetic changes in hub genes (Table 3) and have investigated histone modification patterns of DEGs. Histone modifications are posttranslational modifications of the amino-terminal tails of histone proteins that affect nucleosome structures and gene accessibility to TFs. Histone modification thus affects downstream molecular interactions, thereby affecting patterns of gene expression. We report several histone modification sites present within the hub genes, many of which are already known to be associated with several neurodegenerative diseases [25]. The identification of these known modifications in genes further validates the discovery of the novel DEGs and hub genes that we have identified in this investigation. Our analysis also revealed that differentially expressed DEGs, regulatory TFs, and miRNAs that strongly influence gene expression at the transcriptional and post-transcriptional levels (Table 4-5).

The SREBF2 is a cholesterol regulating genes and significantly increased mRNA levels expression were observed in the late-onset $\mathrm{AD}$ in the brain and blood microarray observations suggesting SREBF2 as biomarkers of $\mathrm{AD}$ at pathological and gene expression levels [26]. In another study evaluated the SREBF2 mRNA level expression in neurodegenerative prion disease. Significantly increased expression of SREBF2 was in prion-infected neuron cells suggesting cholesterogenic upregulation as a neuronal response to prion infection, emphasizing cholesterol biosynthesis critical pathways in prion disease [27]. The genetic variant was studied to determine the effects of rs7120118 variation in the NR1H3 gene on the progression of AD. A significant increase in the mRNA levels of NRIH3 among the AD patients was found by qPCR analysis. Overall, these data suggest that the CT genotype of rs7120118 associated with increased mRNA levels of NR1H3, but the disease severity does not affect NR1H3 expression [28]. Additionally, association analysis of common variants in NR1H3 identified rs2279238 conferring a 1.35-fold increased risk of developing progressive MS. Protein expression analysis revealed that mutant NR1H3 alters gene expression profiles, suggesting a disruption in transcriptional regulation as one of the mechanisms underlying MS pathogenesis. Novel medications based on NR1H3 models are expected to provide symptomatic relief and halt 
disease progression by reducing the inflammatory response and promoting remyelination [29]. The genetic polymorphism in NR1H2 may contribute to the pathogenesis of AD [30]. The exome sequencing and functional studies revealed the genetic variants of PRDM1 in Crohn's disease [31]. PRDM1 was associated with systemic lupus erythematosus (SLE) [32]. There is a link between cerebral inflammation and degeneration in SLE [33], but inverse relations suggested for SLE and Parkinson's disease patients since SLE had a decreased risk of subsequent Parkinson's disease [34]. However, the study indicates that the risk of dementia may be elevated in individuals with SLE, an autoimmune disease affecting a range of systems including the peripheral and central nervous system concluding SLE is significantly associated with dementia [35]. WDR1 is associated with adaptive immunity highlighting its central role in immunologic synapses [36] and cardiovascular diseases [36, 37]. GNL2 plays a role in the neurogenesis of retina in Zebrafish [38]. Gene Ontology (GO) annotations related to gene RPS9 and RPS 12 include structural constituent of ribosome according to genecards database, but the role of these ribosomal proteins in the neurodegenerative disease is obscure. The role of XBP1 in neurodegeneration remains controversial and appears to be disease-specific. XBP1 occupancy was observed on the promoters of genes linked to neurodegenerative pathologies, including AD [39], although the relevance of these events remains speculative. Indeed, XBP1 activates a plethora of target genes involved in a variety of physiological functions, including neuronal plasticity [39, 40, 41], suggesting an important role during the branching and maturation of developing neurons. Accumulation of unfolded or misfolded proteins in the ER leads to an ER stress response, which is characteristic of cells with a high level of secretory activity and is implicated in a variety of disease conditions such as AD [42]. Hub protein PDE4D was particularly noteworthy since recent studies have suggested that phosphodiesterases are promising therapeutic drug targets in AD [43].

miRNAs play important roles in gene regulation, and there is emerging evidence demonstrating their potential for use as biomarkers for $\mathrm{AD}$ and other diseases; it is likely, therefore, that miRNAs play significant roles in the pathogenic process underlying AD [44, 45]. Indeed, such roles have been suggested for miR-518e and miR-518a-3p in AD [45,46]. Similarly, miR-518c may also be a useful biomarker for Parkinson's disease [46], while miR$518 \mathrm{~b}$ is dysregulated in esophageal carcinoma [47].

\subsubsection{Limitation of the study.}

Due to various bioinformatics analyses in the data provided in this report, consideration should be given in the interpretation of these findings. Probably, in future clinical trials with samples from patients with $\mathrm{AD}$, the findings achieved are therefore, will be validated. Such specimens are sadly not available at present. Furthermore, considering the nature of this study relies on information gathered at different sites, site-to-site disparities are likely to affect the results like differences in microarray platforms, blood gathering, and RNA extraction techniques. Because the population is different in both datasets, they may influence the results. Although none of the studies documented mixed pathologies, comorbidities diseases and the use of drugs may also have affected the findings. 


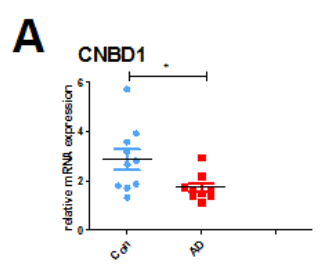

E
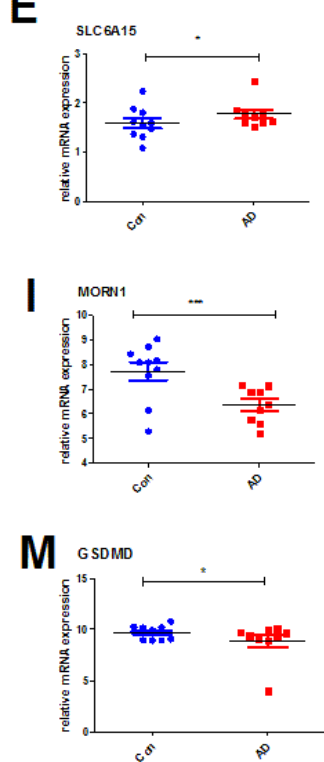

B

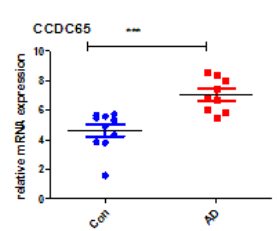

$\mathbf{F}$

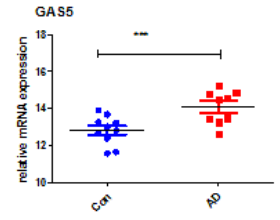

$\mathbf{J}$

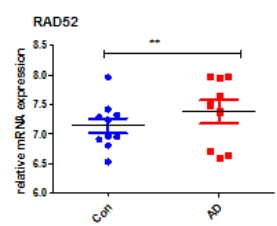

C pose

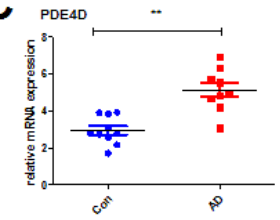

G

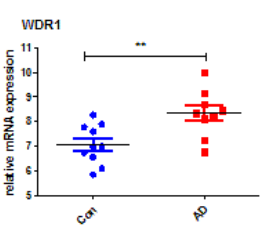

K

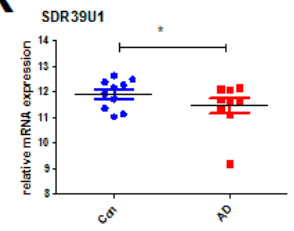

D мтния

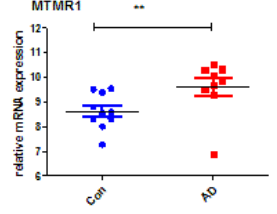

H

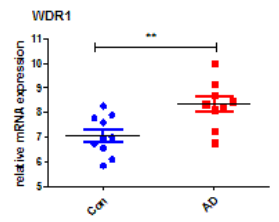

L

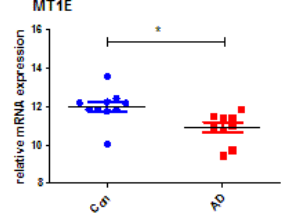

Figure 4. Fig shows significant differential expression of proposed candidate blood and brain genes in an independent blood gene expression data (GSE97760) of advanced Alzheimer's disease (p-value < 0:05). Note:

Con=control, $\mathrm{AD}=\mathrm{Alzh}$ imer's disease, $\mathrm{A}=\mathrm{CNBD} 1, \mathrm{~B}=\mathrm{CCDC65}, \mathrm{C}=\mathrm{PDE} 4 \mathrm{D}, \mathrm{D}=\mathrm{MTMR} 1, \mathrm{E}=\mathrm{SLC6A15}$,

$\mathrm{F}=\mathrm{GAS} 5, \mathrm{G}=\mathrm{WDR} 1, \mathrm{H}=\mathrm{MORN1}$, I=RAD52, J=SDR39U1, K=NPHP4, L=MT1E, M=GSDMD.

Table 6. Cross-validation of proposed candidate blood and brain genes in an independent blood gene expression data (GSE97760) of advanced Alzheimer's disease.

\begin{tabular}{|c|c|c|}
\hline Gene Symbol & P-value in GSE97760 (blood AD data) & Log2 Fold Change \\
\hline CNBD1 & 0.0202 & -1.004 \\
\hline SUCLG2-AS1 & - & - \\
\hline CCDC65 & 0.0002 & 2.454 \\
\hline PDE4D & 0.0043 & 0.992 \\
\hline MTMR1 & 0.0027 & 0.789 \\
\hline $\mathrm{C} 3$ & - & - \\
\hline SLC6A15 & 0.0441 & 0.290 \\
\hline LINC01806 & - & - \\
\hline FRG1JP & - & - \\
\hline HSD17B1 & 0.0577 & -0.438 \\
\hline GAS5 & 0.0003 & 1.424 \\
\hline RPS5 & 0.3599 & 0.157 \\
\hline VKORC1 & 0.4937 & 0.230 \\
\hline GLE1 & 0.7641 & -0.046 \\
\hline WDR1 & 0.0118 & 1.229 \\
\hline RPL12 & 0.6454 & 0.054 \\
\hline MORN1 & 0.0009 & -1.487 \\
\hline RAD52 & 0.0088 & 1.661 \\
\hline SDR39U1 & 0.0484 & -0.371 \\
\hline NPHP4 & 0.0012 & -1.518 \\
\hline MT1E & 0.0138 & -1.0481 \\
\hline SORD & 0.7501 & 0.102 \\
\hline LINC00638 & - & - \\
\hline MCM3AP-AS1 & 0.0703 & 0.505 \\
\hline GSDMD & 0.0456 & -1.0147 \\
\hline RPS9 & 0.2854 & -0.320 \\
\hline GNL2 & 0.1440 & 0.381 \\
\hline
\end{tabular}




\section{Conclusions}

In the present study, we analyzed blood and brain transcriptomic and eQTL data to identify common DEGs between these two tissues in Alzheimer's disease. We integrated these common DEGs into pathway analysis for protein-protein interactions, TFs, and miR-NAs. Nine common DEGs were identified from microarray data of blood and brain. We also identified 18 eQTL genes common to blood cells and brain cells. Neurodegeneration associated molecular signaling pathways and several miRNAs were identified as putative transcriptional and posttranscriptional regulators of the DEGs we identified. In addition, several histone modification sites of hub proteins were also identified. Thus, we have identified potential biomarker transcripts that are commonly dysregulated in both blood cells and brain tissues. We propose that these biomarkers may enable the rapid and cost-effective assessment of blood sample analysis for the diagnosis of AD. This novel approach to identify markers can be employed in easily accessible tissue (blood) to assess its expression in an inaccessible tissue (brain) and is one that could be applied to other related clinical problems. We now propose a more detailed validation of this approach and of the putative biomarker transcripts we have identified with clinical-based investigations.

\section{Funding}

This research received no external funding.

\section{Acknowledgments}

This research has no acknowledgment.

\section{Conflicts of Interest}

The authors declare no conflict of interest.

\section{References}

1. Rahman, M.R.; Islam, T.; Turanli, B.; Zaman, T.; Faruquee, H.M.; Rahman, M.M.; Mollah, M.N.H.; Nanda, R.K.; Arga, K.Y.; Gov, E.; Moni, M.A. Network-based approach to identify molecular signatures and therapeutic agents in Alzheimer's disease. Computational Biology and Chemistry 2019, 78, 431-439, https://doi.org/10.1016/j.compbiolchem.2018.12.011.

2. Alzheimer's, A. 2019 Alzheimer's disease facts and figures. Alzheimer's \& Dementia 2019, 15, 321-387, https://doi.org/10.1016/j.jalz.2019.01.010.

3. Rahman, M.R.; Islam, T.; Zaman, T.; Shahjaman, M.; Karim, M.R.; Huq, F.; Quinn, J.M.W.; Holsinger, R.M.D.; Gov, E.; Moni, M.A. Identification of molecular signatures and pathways to identify novel therapeutic targets in Alzheimer's disease: Insights from a systems biomedicine perspective. Genomics 2020, 112, 1290-1299, https://doi.org/10.1016/j.ygeno.2019.07.018.

4. Dunckley, T.; Beach, T.G.; Ramsey, K.E.; Grover, A.; Mastroeni, D.; Walker, D.G.; LaFleur, B.J.; Coon, K.D.; Brown, K.M.; Caselli, R.; Kukull, W.; Higdon, R.; McKeel, D.; Morris, J.C.; Hulette, C.; Schmechel, D.; Reiman, E.M.; Rogers, J.; Stephan, D.A. Gene expression correlates of neurofibrillary tangles in Alzheimer's disease. Neurobiology of Aging 2006, 27, 1359-1371, https://doi.org/10.1016/j.neurobiolaging.2005.08.013.

5. K Tang, R. and Liu, H. Identification of temporal characteristic networks of peripheral blood changes in Alzheimer's disease based on weighted gene co-expression network analysis. Frontiers in aging neuroscience 2019, 11, 83, https://doi.org/10.3389/fnagi.2019.00083.

6. Wang, L.; Liu, Z.P. Detecting diagnostic biomarkers of Alzheimer's disease by integrating gene expression data in six brain regions. Frontiers in genetics 2019, 10, 157, https://doi.org/10.3389/fgene.2019.00157.

7. Liu, L.; Wu, Q.; Zhong, W.; Chen, Y.; Zhang, W.; Ren, H.; Sun, L.; Sun, J. Microarray Analysis of Differential Gene Expression in Alzheimer's Disease Identifies Potential Biomarkers with Diagnostic 
Value. Medical Science Monitor: International Medical Journal of Experimental and Clinical Research 2020, 26, e919249-1, DOI: 10.12659/MSM.919249.

8. Lista, S.; Bottero, V.; Potashkin, J.A. Meta-Analysis of Gene Expression Changes in the Blood of Patients with Mild Cognitive Impairment and Alzheimer's Disease Dementia. International journal of molecular sciences 2019, 20, 5403, https://doi.org/10.3390/ijms20215403.

9. Park, Y.H.; Hodges, A.; Risacher, S.L.; Lin, K.; Jang, J.W.; Ahn, S.; Kim, S.; Lovestone, S.; Simmons, A.; Weiner, M.W.; Saykin, A.J. Dysregulated Fc gamma receptor-mediated phagocytosis pathway in Alzheimer's disease: network-based gene expression analysis. Neurobiology of aging 2020, 88, 24-32, https://doi.org/10.1016/j.neurobiolaging.2019.12.001.

10. Shigemizu, D.; Mori, T.; Akiyama, S.; Higaki, S.; Watanabe, H.; Sakurai, T.; Niida, S.; Ozaki, K. Identification of potential blood biomarkers for early diagnosis of Alzheimer's disease through RNA sequencing analysis. Alzheimer's Research \& Therapy 2020, 12, 1-12, https://doi.org/10.1186/s13195-02000654-X.

11. Sun, Y., Lin, J. and Zhang, L., 2019. The application of weighted gene co-expression network analysis in identifying key modules and hub genes associated with disease status in Alzheimer's disease. Annals of Translational Medicine 2019, 7, 800, http://dx.doi.org/10.21037/atm.2019.12.59.

12. Devall, M.; Roubroeks, J.; Mill, J.; Weedon, M.; Lunnon, K. Epigenetic regulation of mitochondrial function in neurodegenerative disease: New insights from advances in genomic technologies. Neuroscience Letters 2016, 625, 47-55, https://doi.org/10.1016/j.neulet.2016.02.013.

13. Barrett, T.; Wilhite, S.E.; Ledoux, P.; Evangelista, C.; Kim, I.F.; Tomashevsky, M.; Marshall, K.A.; Phillippy, K.H.; Sherman, P.M.; Holko, M.; Yefanov, A.; Lee, H.; Zhang, N.; Robertson, C.L.; Serova, N.; Davis, S.; Soboleva, A. NCBI GEO: archive for functional genomics data sets-update. Nucleic Acids Res 2012, 41, D991-D995, https://doi.org/10.1093/nar/gks1193.

14. Kuleshov, M.V.; Jones, M.R.; Rouillard, A.D.; Fernandez, N.F.; Duan, Q.; Wang, Z.; Koplev, S.; Jenkins, S.L.; Jagodnik, K.M.; Lachmann, A.; McDermott, M.G.; Monteiro, C.D.; Gundersen, G.W.; ' 'Ma'ayan, A. Enrichr: a comprehensive gene set enrichment analysis web server 2016 update. Nucleic Acids Res 2016, 44, W90-W97, https://doi.org/10.1093/nar/gkw377.

15. Szklarczyk, D.; Morris, J.H.; Cook, H.; Kuhn, M.; Wyder, S.; Simonovic, M.; Santos, A.; Doncheva, N.T.; Roth, A.; Bork, P.; Jensen, L.J.; von Mering, C. The STRING database in 2017: quality-controlled proteinprotein association networks, made broadly accessible. Nucleic Acids Res 2016, 45, D362-D368, https://doi.org/10.1093/nar/gkw937.

16. Xia, J.; Gill, E.E.; Hancock, R.E.W. NetworkAnalyst for statistical, visual and network-based meta-analysis of gene expression data. Nature Protocols 2015, 10, 823-844, https://doi.org/10.1038/nprot.2015.052.

17. Zhang, Y.; Lv, J.; Liu, H.; Zhu, J.; Su, J.; Wu, Q.; Qi, Y.; Wang, F.; Li, X. HHMD: the human histone modification database. Nucleic Acids Res 2009, 38, D149-D154, https://doi.org/10.1093/nar/gkp968.

18. Wingender, E.; Dietze, P.; Karas, H.; Knüppel, R. TRANSFAC: A Database on Transcription Factors and Their DNA Binding Sites. Nucleic Acids Res 1996, 24, 238-241, https://doi.org/10.1093/nar/24.1.238.

19. Khan, A.; Fornes, O.; Stigliani, A.; Gheorghe, M.; Castro-Mondragon, J.A.; van der Lee, R.; Bessy, A.; Chèneby, J.; Kulkarni, S.R.; Tan, G.; Baranasic, D.; Arenillas, D.J.; Sandelin, A.; Vandepoele, K.; Lenhard, B.; Ballester, B.; Wasserman, W.W.; Parcy, F.; Mathelier, A. JASPAR 2018: update of the open-access database of transcription factor binding profiles and its web framework. Nucleic Acids Res 2017, 46, D260D266, https://doi.org/10.1093/nar/gkx1126.

20. Hsu, S.D.; Lin, F.M.; Wu, W.Y.; Liang, C.; Huang, W.C.; Chan, W.L.; Tsai, W.T.; Chen, G.Z.; Lee, C.J.; Chiu, C.M.; Chien, C.H.; Wu, M.C.; Huang, C.Y.; Tsou, A.P.; Huang, H.D. miRTarBase: a database curates experimentally validated microRNA-target interactions. Nucleic Acids Res 2010, 39, D163-D169, https://doi.org/10.1093/nar/gkq1107.

21. Qi, T.; Wu, Y.; Zeng, J.; Zhang, F.; Xue, A.; Jiang, L.; Zhu, Z.; Kemper, K.; Yengo, L.; Zheng, Z.; Agbessi, M.; Ahsan, H.; Alves, I.; Andiappan, A.; Awadalla, P.; Battle, A.; Beutner, F.; Jan Bonder, M.; Boomsma, D.; Christiansen, M.; Claringbould, A.; Deelen, P.; Esko, T.; Favé, M.-J.; Franke, L.; Frayling, T.; Gharib, S.; Gibson, G.; Hemani, G.; Jansen, R.; Kähönen, M.; Kalnapenkis, A.; Kasela, S.; Kettunen, J.; Kim, Y.; Kirsten, H.; Kovacs, P.; Krohn, K.; Kronberg-Guzman, J.; Kukushkina, V.; Kutalik, Z.; Lee, B.; Lehtimäki, T.; Loeffler, M.; Marigorta, U.M.; Metspalu, A.; Milani, L.; Müller-Nurasyid, M.; Nauck, M.; Nivard, M.; Penninx, B.; Perola, M.; Pervjakova, N.; Pierce, B.; Powell, J.; Prokisch, H.; Psaty, B.; Raitakari, O.; Ring, S.; Ripatti, S.; Rotzschke, O.; Ruëger, S.; Saha, A.; Scholz, M.; Schramm, K.; Seppälä, I.; Stumvoll, M.; Sullivan, P.; Teumer, A.; Thiery, J.; Tong, L.; Tönjes, A.; van Dongen, J.; van Meurs, J.; Verlouw, J.; Völker, U.; Võsa, U.; Yaghootkar, H.; Zeng, B.; Marioni, R.E.; Montgomery, G.W.; Deary, I.J.; Wray, N.R.; Visscher, P.M.; McRae, A.F.; Yang, J.E.Q.C. Identifying gene targets for brain-related traits using transcriptomic and methylomic data from blood. Nature Communications 2018, 9, 1-12, https://doi.org/10.1038/s41467-018-04558-1.

22. Sevimoglu, T.; Arga, K.Y. The role of protein interaction networks in systems biomedicine. Computational and structural biotechnology journal 2014, 11, 22-27, https://doi.org/10.1016/j.csbj.2014.08.008. 
23. Garcia-Esparcia, P.; Sideris-Lampretsas, G.; Hernandez-Ortega, K.; Grau-Rivera, O.; Sklaviadis, T.; Gelpi, E.; Ferrer, I. Altered mechanisms of protein synthesis in frontal cortex in Alzheimer disease and a mouse model. American journal of neurodegenerative disease 2017, 6, 15-25.

24. Cacabelos, R.; Torrellas, C. Epigenetics of Aging and Alzheimer's Disease: Implications for Pharmacogenomics and Drug Response. International Journal of Molecular Sciences 2015, 16, 3048330543, https://doi.org/10.3390/ijms161226236.

25. Pattaroni, C.; Jacob, C. Histone Methylation in the Nervous System: Functions and Dysfunctions. Molecular Neurobiology 2013, 47, 740-756, https://doi.org/10.1007/s12035-012-8376-4.

26. Picard, C.; Julien, C.; Frappier, J.; Miron, J.; Théroux, L.; Dea, D.; Breitner, J.C.S.; Poirier, J. Alterations in cholesterol metabolism-related genes in sporadic "” Alzheimer's disease. Neurobiology of Aging 2018, 66, 180.e181-180.e189, https://doi.org/10.1016/j.neurobiolaging.2018.01.018.

27. Bach, C.; Gilch, S.; Rost, R.; Greenwood, A.D.; Horsch, M.; Hajj, G.N.; Brodesser, S.; Facius, A.; Schädler, S.; Sandhoff, K.; Beckers, J. Prion-induced activation of cholesterogenic gene expression by Srebp2 in neuronal cells. Journal of Biological Chemistry 2009, 284, 31260-31269, https://doi.org/10.1074/jbc.M109.004382.

28. Natunen, T.; Martiskainen, H.; Sarajärvi, T.; Helisalmi, S.; Pursiheimo, J.-P.; Viswanathan, J.; Laitinen, M.; Mäkinen, P.; Kauppinen, T.; Rauramaa, T.; Leinonen, V.; Alafuzoff, I.; Haapasalo, A.; Soininen, H.; Hiltunen, M. Effects of NR1H3 Genetic Variation on the Expression of Liver X Receptor $\alpha$ and the Progression of Alzheimer's Disease. PLOS ONE 2013, 8, https://doi.org/10.1371/journal.pone.0080700.

29. Wang, Z.; Sadovnick, A.D.; Traboulsee, Anthony L.; Ross, Jay P.; Bernales, Cecily Q.; Encarnacion, M.; Yee, Irene M.; de Lemos, M.; Greenwood, T.; Lee, Joshua D.; Wright, G.; Ross, Colin J.; Zhang, S.; Song, W.; Vilariño-Güell, C. Nuclear Receptor NR1H3 in Familial Multiple Sclerosis. Neuron 2016, 90, 948-954, https://doi.org/10.1016/j.neuron.2016.04.039.

30. Adighibe, O.; Arepalli, S.; Duckworth, J.; Hardy, J.; Wavrant-De Vrièze, F. Genetic variability at the LXR gene (NR1H2) may contribute to the risk of "' Alzheimer's disease. Neurobiology of Aging 2006, 27, 14311434, https://doi.org/10.1016/j.neurobiolaging.2005.08.010.

31. Ellinghaus, D.; Zhang, H.; Zeissig, S.; Lipinski, S.; Till, A.; Jiang, T.; Stade, B.; Bromberg, Y.; Ellinghaus, E.; Keller, A.; et al., Association between variants of PRDM1 and NDP52 and " Crohn's disease, based on exome sequencing and functional studies, Gastroenterology 2013,145, 339-347, https://doi.org/10.1053/j.gastro.2013.04.040.

32. Gateva, V.; Sandling, J.K.; Hom, G.; Taylor, K.E.; Chung, S.A.; Sun, X.; Ortmann, W.; Kosoy, R.; Ferreira, R.C.; Nordmark, G.; Gunnarsson, I.; Svenungsson, E.; Padyukov, L.; Sturfelt, G.; Jönsen, A.; Bengtsson, A.A.; Rantapää-Dahlqvist, S.; Baechler, E.C.; Brown, E.E.; Alarcón, G.S.; Edberg, J.C.; Ramsey-Goldman, R.; McGwin, G.; Reveille, J.D.; Vilá, L.M.; Kimberly, R.P.; Manzi, S.; Petri, M.A.; Lee, A.; Gregersen, P.K.; Seldin, M.F.; Rönnblom, L.; Criswell, L.A.; Syvänen, A.-C.; Behrens, T.W.; Graham, R.R. A largescale replication study identifies TNIP1, PRDM1, JAZF1, UHRF1BP1 and IL10 as risk loci for systemic lupus erythematosus. Nature Genetics 2009, 41, 1228-1233, https://doi.org/10.1038/ng.468.

33. Trysberg, E.; Tarkowski, A. Cerebral inflammation and degeneration in systemic lupus erythematosus. Current Opinion in Rheumatology 2004, 16, 527-533, https://doi.org/10.1097/01.bor.0000135451.85671.14.

34. Liu, F.C.; Huang, W.Y.; Lin, T.Y.; Shen, C.H.; Chou, Y.C.; Lin, C.L.; Lin, K.T.; Kao, C.H. Inverse Association of Parkinson Disease With Systemic Lupus Erythematosus: A Nationwide Population-based Study. Medicine 2015, 94, https://doi.org/10.1097/MD.0000000000002097.

35. Gendelman, O.; Tiosano, S.; Shoenfeld, Y.; Comaneshter, D.; Amital, H.; Cohen, A.D.; Amital, D. High proportions of dementia among SLE patients: A big data analysis. International Journal of Geriatric Psychiatry 2018, 33, 531-536, https://doi.org/10.1002/gps.4819.

36. Pfajfer, L.; Mair, N.K.; Jiménez-Heredia, R.; Genel, F.; Gulez, N.; Ardeniz, Ö.; Hoeger, B.; Bal, S.K.; Madritsch, C.; Kalinichenko, A.; Chandra Ardy, R.; Gerçeker, B.; Rey-Barroso, J.; Ijspeert, H.; Tangye, S.G.; Simonitsch-Klupp, I.; Huppa, J.B.; van der Burg, M.; Dupré, L.; Boztug, K. Mutations affecting the actin regulator WD repeat\&\#x2013;containing protein 1 lead to aberrant lymphoid immunity. Journal of Allergy and Clinical Immunology 2018, 142, 1589-1604, https://doi.org/10.1016/j.jaci.2018.04.023.

37. Montenont, E.; Echagarruga, C.; Allen, N.; Araldi, E.; Suarez, Y.; Berger, J.S. Platelet WDR1 suppresses platelet activity and is associated with cardiovascular disease. Blood 2016, 128, 2033-2042, https://doi.org/10.1182/blood-2016-03-703157.

38. Paridaen, J.T.M.L.; Janson, E.; Utami, K.H.; Pereboom, T.C.; Essers, P.B.; van Rooijen, C.; Zivkovic, D.; MacInnes, A.W. The nucleolar GTP-binding proteins Gnl2 and nucleostemin are required for retinal neurogenesis in developing zebrafish. Developmental Biology 2011, 355, 286-301, https://doi.org/10.1016/j.ydbio.2011.04.028.

39. Acosta-Alvear, D.; Zhou, Y.; Blais, A.; Tsikitis, M.; Lents, N.H.; Arias, C.; Lennon, C.J.; Kluger, Y.; Dynlacht, B.D. XBP1 Controls Diverse Cell Type- and Condition-Specific Transcriptional Regulatory Networks. Molecular Cell 2007, 27, 53-66, https://doi.org/10.1016/j.molcel.2007.06.011.

40. Cissé, M.; Duplan, E.; Checler, F. The Transcription Factor XBP1 in Memory and Cognition: implications in Alzheimer's Disease. Molecular Medicine 2016, 22, 905-917, https://doi.org/10.2119/molmed.2016.00229. 
41. Martínez, G.; Vidal, René L.; Mardones, P.; Serrano, Felipe G.; Ardiles, Alvaro O.; Wirth, C.; Valdés, P.; Thielen, P.; Schneider, Bernard L.; Kerr, B.; Valdés, Jose L.; Palacios, Adrian G.; Inestrosa, Nibaldo C.; Glimcher, Laurie H.; Hetz, C. Regulation of Memory Formation by the Transcription Factor XBP1. Cell Reports 2016, 14, 1382-1394, https://doi.org/10.1016/j.celrep.2016.01.028.

42. Cissé, M.; Duplan, E.; Lorivel, T.; Dunys, J.; Bauer, C.; Meckler, X.; Gerakis, Y.; Lauritzen, I.; Checler, F. The transcription factor XBP1s restores hippocampal synaptic plasticity and memory by control of the Kalirin-7 pathway in Alzheimer model. Molecular Psychiatry 2017, 22, 1562-1575, https://doi.org/10.1038/mp.2016.152.

43. Gurney, M.E.; D’Amato, E.C.; Burgin, A.B. Phosphodiesterase-4 (PDE4) Molecular Pharmacology and Alzheimer's Disease. Neurotherapeutics 2015, 12, 49-56, https://doi.org/10.1007/s13311-014-0309-7.

44. Cosín-Tomás, M.; Álvarez-López, M.J.; Companys-Alemany, J.; Kaliman, P.; González-Castillo, C.; Ortuño-Sahagún, D.; Pallàs, M.; Griñán-Ferré, C. Temporal integrative analysis of mRNA and microRNAs expression profiles and epigenetic alterations in female SAMP8, a model of age-related cognitive decline. Frontiers in genetics 2018, 9, https://doi.org/10.3389/fgene.2018.00596.

45. Miya Shaik, M.; Tamargo, I.A.; Abubakar, M.B.; Kamal, M.A.; Greig, N.H.; Gan, S.H. The role of microRNAs in Alzheimer's Disease and Their Therapeutic Potentials. Genes 2018, 9, https://doi.org/10.3390/genes9040174.

46. Khoo, S.K.; Petillo, D.; Kang, U.J.; Resau, J.H.; Berryhill, B.; Linder, J.; Neuman, L.A.; Tan, A.C. Plasmabased circulating MicroRNA biomarkers for '" Parkinson's disease. Journal of ', Parkinson's disease 2012, 2, 321-331, https://doi.org/10.3233/JPD-012144.

47. Zhang, M.; Zhou, S.; Zhang, L.; Zhang, J.; Cai, H.; Zhu, J.; Huang, C.; Wang, J. miR-518b is downregulated, and involved in cell proliferation and invasion by targeting Rap1b in esophageal squamous cell carcinoma. FEBS Letters 2012, 586, 3508-3521, https://doi.org/10.1016/j.febslet.2012.08.007. 